\section{Mentirosos por finura ou a hipocrisia poética da burguesia}

EMÍLIA COSTA

Título: A criada Zerlina. Autor: Hermann Broch. Encenação: João Botelho. Versão: António S. Ribeiro com a colaboração de José Ribeiro da Fonte, a partir da tradução de Suzana Muñoz. Cenografia: Pedro Cabrita Reis. Desenho de luz: Nuno Meira. Sonoplastia: Sérgio Milhano. Interpretação: Luísa Cruz. Produção executiva: Nuno Pratas. Produção: Centro Cultural de Belém e Culturproject. Local e data de estreia: Centro Cultural de Belém, Lisboa, 21 de Fevereiro de 2019.

As pessoas não valem nada. Não é só a pobre rapariga do campo que não vale nada, não, é toda a gente. HERMANN BROCH, A criada Zerlina»

Incapaz de resistir a um bom desafio, João Botelho embarcou, juntamente com Luísa Cruz, na aventura, lançada pelo Centro Cultural de Belém, de transformar A criada Zerlina, excerto da obra-prima literária de Hermann Broch Os inocentes, publicada em 1950, num acontecimento teatral. A potencialidade dramática de um quase monólogo motivou, desde meados do século xx, diversos espectáculos de teatro pelo mundo fora, porém, em Portugal apenas por duas vezes se ousou assumir tal risco: em 1988 pela mão de João Perry, com Eunice Muñoz como protagonista, e em 2015, numa co-encenação de José Roseira e Micaela Cardoso, tendo Micaela igualmente assumido o papel da protagonista.

A surpresa da provocação reside no convite que o Centro Cultural de Belém lançou a um cineasta consagrado no panorama cinematográfico português, como é o caso de João Botelho, que, desde os tempos de estudante em Coimbra, quando integrou o CITAC, o qual chegou a dirigir, não mais teve intervenção directa na criação teatral. Destaca-se, no entanto, que a grande maioria dos filmes que realizou se mostram impregnados de manifestações teatrais, assumidas pelo próprio, como se entre teatro e cinema existisse uma comunhão impossível de quebrar.

Aliás, uma outra experiência profissional com o palco já tinha ocorrido em 2011, quando encenou no São Carlos a ópera Banksters, de Nuno

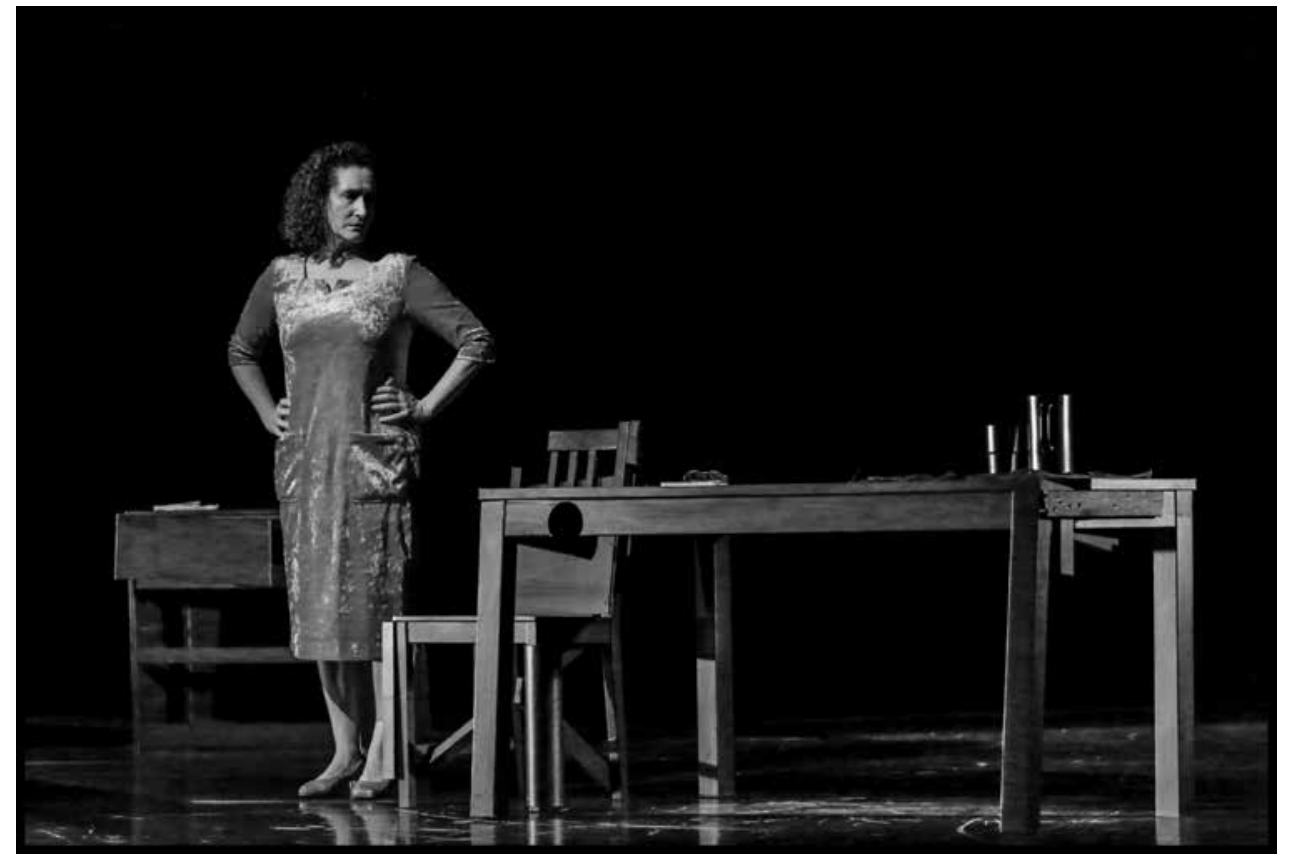

A CRIADA ZERLINA, DE HERMANN BROCH, ENC. JOÃo BOTELHO, FESTIVAL DE ALMADA, 2020 [LUÍSA CRUZ], [F] RUI CARLOS MATEUS

Côrte-Real, com libreto de Vasco Graça Moura, inspirada na peça Jacob e o Anjo, de José Régio.

De igual modo, a adaptação literária é território familiar a Botelho, ainda que na Sétima Arte, como aconteceu nos filmes Hard Times (1985), Filme do desassossego (2010), Os Maias (2014) e Peregrinação (2017).

Talvez por isso, esta incursão de Botelho na dinâmica teatral inspirada na literatura tenha surgido como algo natural, inevitável, apenas surpreendendo por tardia.

Por sua vez, Luísa Cruz desempenhou o seu primeiro monólogo, onde, por opção do encenador e da actriz, não foi incluída na peça a personagem secundária, o senhor A., interlocutor quase silencioso das confissões inesperadas da criada Zerlina, substituído por uma gravação em voz-off da própria Luísa Cruz.

No vértice do encontro entre encenador e actriz, deparamo-nos com um texto magnífico, escrito por um dos mais destacados escritores modernistas, no qual é dada a palavra ao povo, através de uma mulher. E se ouvir o povo representava, à data, algo insólito, ouvi-lo através do pensamento de uma mulher era simplesmente revolucionário. Zerlina impõe-se ao seu interlocutor, obrigando-o a ouvi-la, numa confissão 


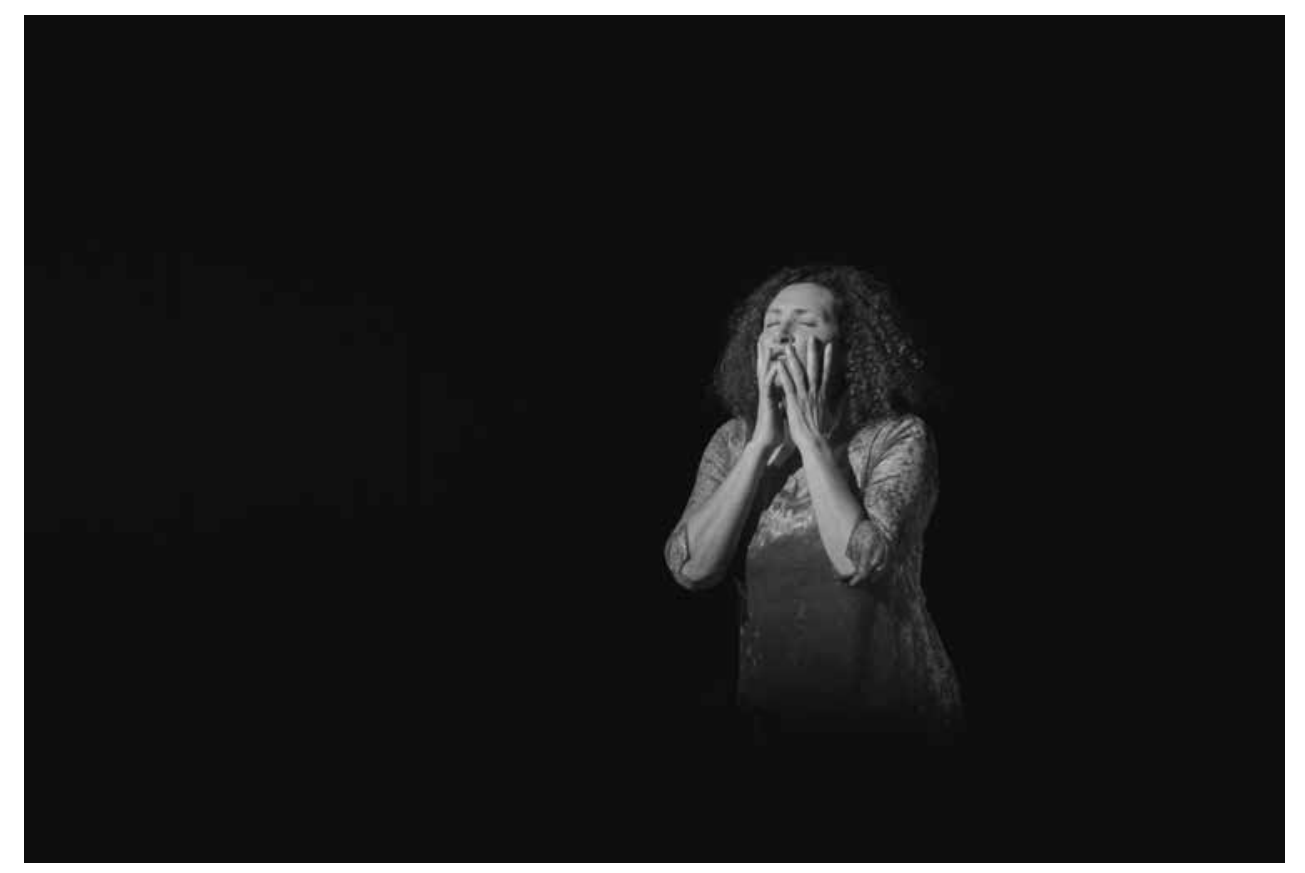

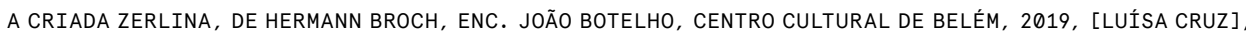
[F] VITORINO CORAGEM

inusitada, revelando-lhe, revelando-nos, os seus cruéis segredos e os seus devaneios sexuais mais íntimos. Através da sua voz, deparamo-nos, não só com um imaginário feminino onde coexistem distintamente amor e puro prazer, como também com uma mulher imune à pureza e inocência de uma criança, insensível a quaisquer manifestações de instinto maternal, direccionando a sua perversidade para esse ser indefeso que lhe foi entregue para cuidar. E essa barbárie é-nos justificada pela vingança que terá de recair sobre o fruto do adultério, numa visão moralista, primária, boçal, que avilta a sexualidade e endeusa a castidade. De repente, na incredulidade daquilo que nos é despudoradamente exibido, os nossos preconceitos estremecem, baralham-se as certezas. Ainda hoje, setenta anos depois.

Por outro lado, a luta de classes, essa dialéctica opressiva, injusta, dramática, é-nos arremessada à cara, em forma de bofetada. É verdade que já não nos identificamos com os barões e baronesas retratados, que, aliás, já se encontravam em declínio, agora é a burguesia sem título nobiliárquico que domina, mas, de qualquer modo, em ambos os períodos, idênticas distinções sociais, similares impossibilidades de fuga ao acaso do nascimento, análogas marcas da pobreza, no corpo, nas mãos.

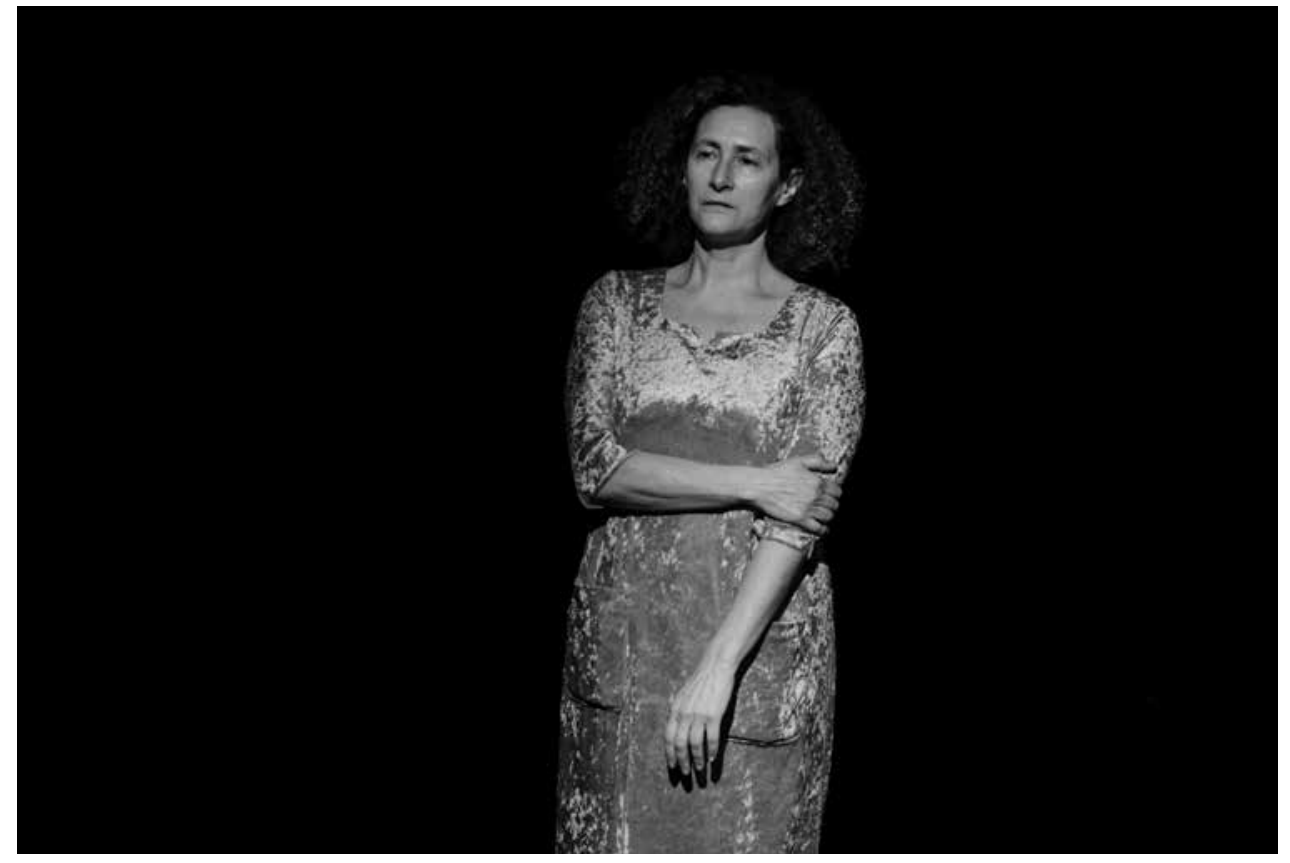

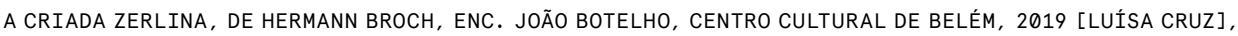
[F] VITORINO CORAGEM

Zerlina é cruel e desumana, como é desumano e cruel o modo como é obrigada a viver: sem casa, sem filhos, sem amor, vivendo na vida dos outros.

Na revelação da revolta da criada, desse ser sem identidade e ressentido, compreendemos que a exploração apenas funciona na crença da superioridade (seja de força, de sangue, de casta, de educação, de inteligência ou de moral), dos exploradores sobre os explorados e que, quando se dá a suspensão dessa crença, a brutalidade contida emerge. Não é possível manter a servidão sem manter as distâncias; por isso, a democracia, apanágio da igualdade, terá sempre muita dificuldade em sobreviver durante os períodos de grandes clivagens sociais e económicas, visto que, ao ser incapaz de concretizar a igualdade que promove, se transforma em propaganda estéril, facilmente derrotada por ideologias securitárias e autocráticas, que permitem o ressurgir dessa crença, fundamento de toda a opressão.

Não há assim heróis nem vilões neste magnífico trecho, apenas seres frágeis, perturbados, desesperados, em busca de um sentido que lhes apazigue a existência, seja ele, o amor, o sexo, a castidade ou a vingança. 


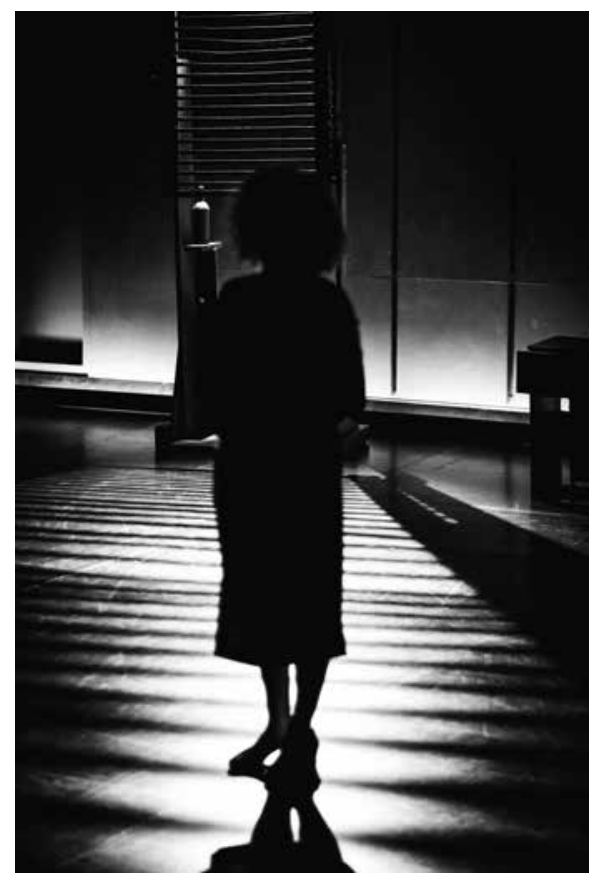

A CRIADA ZERLINA, DE HERMANN BROCH,

ENC. JOÃO BOTELHO, CENTRO CULTURAL DE BELÉM, 2019 ENC. JOÁO BOTELHO, CENTRO CULTURAL DE
[LUISAA CRUZ], [F] VITORINO CORAGEM

Era a este texto que encenador e actriz tinham de dar expressão, aquele levando o cinema para o teatro, esta aplicando a sua longa experiência nesta controversa personagem.

Botelho, coadjuvado por Pedro Cabrita Reis, num cenário abstraccionista, invocador de um estilismo desumanizado, transportou-nos para um universo nubloso, nocturno, povoado de sombras, numa penumbra que melhor destaca o vermelho do vestido de veludo de Zerlina, que nem nas vestes se assemelha a uma criada, apenas na sua fadiga, no seu cansaço, no peso do seu corpo destruído pelo trabalho. A narrativa é pontuada por momentos de total escuridão, como se apenas no silêncio da noite fosse possível avançar, evoluir. $\mathrm{E}$ apesar de estarmos perante um plano geral, diferentemente daquilo que acontece no cinema, Botelho, com mestria, num jogo exemplar de luz, capta-nos a atenção na direcção pretendida, levando-nos a olhar para o quadro inexistente do juiz Conselheiro.

E porque não estamos num espectáculo de época, nem se procura imitar a realidade ou apelar à identificação, antes sim, ao distanciamento, à reflexão e ao pensamento, da música erudita ${ }^{1}$, que preenche os pontuais momentos sonoros da peça, passa-se, como momento final, para a música electrónica ${ }^{2}$ dos dias de hoje, para nos recordar que estamos aqui e agora, neste momento, no presente, e que é sobre a actualidade que nos compete reflectir e agir.

Por fim, resta-nos falar de Luísa Cruz, do seu desempenho, da sua entrega. Depois de ter estreado no Centro Cultural de Belém, A criada Zerlina teve uma passagem pelo Teatro Aberto e, finalmente, integrou o programa do $37 .^{\circ}$ Festival de Almada, em Julho de 2020. Foi aí que assistimos, numa noite, em plena pandemia de covid-19, de máscara e sem ar condicionado, a um inesquecível monólogo.

Durante cerca de hora e meia, Luísa Cruz preencheu sozinha o palco, contracenando, num espaço quase despido de objectos, com o seu próprio corpo, avançando e recuando na direcção do espectador, olhando-o nos olhos, assumindo o sofrimento e a crueldade da sua personagem, numa dignidade pungente, sem defesas, exposta, ora subtil e intelectual, ora ordinária e ignorante. Zerlina é Luísa Cruz. E Luísa Cruz é Zerlina, a Baronesa, o Senhor de Juna, o juiz Conselheiro, o senhor A. e Hermann Broch. Luísa Cruz somos nós. A humanidade na sua inexorável contradição.

Durante hora e meia, o silêncio foi preenchido pela modulação vocal de Luísa Cruz e pontuado por breves separadores musicais, sem que uma única tosse, um único ruído tivesse interferido, num silêncio sepulcral onde apenas Zerlina e os seus fantasmas se fizeram ouvir. Momentos raros, estes. Mas quando isso acontece, sabemos que a magia do teatro se realizou. Uma magia que nenhuma outra linguagem artística consegue, não deste modo, não nesta congregação colectiva. 